\title{
Women Studies In Engineering Education: Content Analysis In Three Referred Journals
}

Pao-Nan Chou, National University of Tainan, Taiwan

\begin{abstract}
Little is known about the research characteristics of past women studies in engineering education. In order to add knowledge base about the advanced development of women studies in current engineering education research, the purpose of the study is to investigate research characteristics of past women studies published in three referred engineering education journals from 2000 to 2009 and to propose specific research patterns for engineering educators. This study adopts a four-stage model of content analysis to analyze the collected data. The model contains four major research procedures, including sampling, conceptualization, operationalization, and coding verification. The findings show that the research patterns of past women studies are: (1) The number of annual publication for women studies is limited; (2) Few scholars from South America and Asia-Pacific engage in women studies; (3) Mixed-methods methodology is the less used research design in women studies; (4) Female engineering faculty and $\mathrm{K}-12$ female students are not focuses for engineering educators; (5) Researchers tend to focus on general engineering; and (6) The current trend of research topic centers on female college engineering students' learning experiences. The research patterns serve as research guidelines for engineering educators who try to explore women issues in engineering education. It is expected that future studies may fill the identified research gaps. Additional in-depth discussion of women studies may be increased as a result of this research.
\end{abstract}

Keywords: Women Studies; Content Analysis; Bibliometric Analysis; Engineering Education

\section{INTRODUCTION}

ccording to one special report (JEE, 2006), five potential research themes for future engineering education studies can be: (a) engineering epistemologies, (b) engineering learning mechanisms, (c) engineering learning systems, (d) engineering diversity and inclusiveness, and (e) engineering assessment. Under the theme of engineering diversity and inclusiveness, women studies, which focus on female groups' learning interests, are major research topics.

However, despite some policies and strategies created to promote women's learning interests in the field of engineering education, Beddoes and Borrego (2011) found that the efforts to explore female groups' (i.e. college students, engineers or faculty) issues are not enough. They contended that "women remain underrepresented in engineering..." (p. 281). Similarly, Dobson (2012) considered that engineering is still a male-dominated discipline in the $21^{\text {st }}$ century. Therefore, a continuous exploration for women research is necessary.

Content analysis is one of bibliometric methods that can systematically analyze a large number of message contents (i.e. scientific literature) through quantitative data representation (Neuendorf, 2002). In recent years, several engineering educators have begun to employ the content analysis to explore research trends in engineering education. For instance, Jesiek et al. (2011) used the content analysis to map out the global research trend in engineering education. 
While examining existing literature in the area of engineering education, literature analysis only identifies one past research that applied the content analysis into women studies. In Beddoes and Borrego's (2011) study, five feminist theories were used as a discussion point to analyze scientific literature related to women studies. However, the main idea in the study all emphasizes the feminist theory. Little is known about the research characteristics of past women studies in engineering education. The identification of the research characteristics may yield several research patterns, which can allow engineering educators to obtain a whole picture of the current trend of women research.

Based on the above discussion, in order to add knowledge base about the advanced development of women studies in engineering education, the purpose of the study is to investigate research characteristics of past women studies published in three referred engineering education journals from 2000 to 2009 and to propose specific research patterns for engineering educators. Specifically, the research questions of the current study are:

1. How many women studies have appeared in engineering education journals?

2. What diverse nationalities represent contributors to women studies in engineering education journals?

3. What research methods have been used for past women studies in engineering education journals?

4. What educational levels do research subjects apply as represented by women studies in engineering education journals?

5. What types of engineering disciplines have been discussed in women studies?

6. What kinds of research topics related to women studies have been published in engineering education journals?

\section{RESEARCH METHOD}

are:

This study adopted Chou and Chang's (2010) models of content analysis. Four major research procedures

1. Sampling (content selection): This study only selected research-based papers published in three referred engineering education journals from 2000 to 2009 for further analysis. The target journals are Journal of Engineering Education (JEE), International Journal of Engineering Education (IJEE), European Journal of Engineering Education (EJEE). Articles, such as book review, workshop (or conference) summary, editorial (or guest editorial), and prize lecture, were excluded. Totally, 51 research articles were identified. The rationale of choosing those three referred journals as a sampling source is that journal administrators have already proposed several special issues related to women studies, which in turn increases the publication number of women studies.

2. Conceptualization (question specification): Six research questions discussed earlier were proposed. This study focused on six research areas: (a) quantity of research, (b) author's geographical affiliation, (c) research method, (d) research subject, (e) engineering discipline, and (f) research topic.

3. Operationalization (variable identification): Based on research questions, a coding book, which summarizes coding strategies, was created. In this study, except for research discipline, the variable range in quantity of research is one to ten; in author's geographical affiliation is one to seven; in research method is one to four; in research subject is one to four; in research topic is one to four.

4. Coding verification (reliability check): This study employed a triangulation method to verify coding strategies. During coding process, two graduate students were collaboratively engaged in processing selected journal articles. Subsequently, finished coding data was submitted to an experienced professor in engineering education to corroborate evidence.

\section{CODING BOOK}

The coding book serves as a research guideline which depicts the categorization principles to deal with six research questions described earlier. By following these principles, collected data is processed in a systematic way. 


\section{Quantity of Research}

This study analyzed research articles published in three engineering education journals from 2000 to 2009 (a ten-year period). Each women study's publishing date was summarized for further analysis according to the chronological order.

\section{Author's Geographical Affiliation}

Authors' geographical affiliations represent seven classification areas: (a) North America (e.g. US), (b) South America (e.g. Mexico); (c) Europe (e.g. Germany), (d) Middle East (e.g. Turkey), (e) Asia-Pacific (e.g. Korea), (f) South Asia (e.g. Australia), and (g) Africa (e.g. South Africa). This study only analyzes each article's first author's affiliation.

\section{Research Method}

Four elements in research method are: theoretical inquiry, quantitative-based, qualitative-based, and mixedmethods. Detailed description of the coding variables summarized in Table 1.

Table 1: Research Method's Coding Strategy

\begin{tabular}{|l|l|}
\hline \multicolumn{1}{|c|}{ Category } & \multicolumn{1}{c|}{ Description } \\
\hline (a) Theoretical inquiry & A study aims to propose new ideas without assessment data. \\
\hline (b) Quantitative-based & A study aims to investigate specific topics by providing quantitative assessment data. \\
\hline (c) Qualitative-based & A study aims to investigate specific topics by providing qualitative assessment data. \\
\hline (d) Mixed-methods & A study aims to investigate specific topics by providing quantitative and qualitative assessment data. \\
\hline
\end{tabular}

\section{Research Subject}

Research subjects analyzed in this study are: (a) no participant, (b) female engineering faculty, (c) female engineer, (d) female college or graduate engineering student, (e) male and female college engineering student (i.e. gender comparison analysis), and (f) K-12 female student.

\section{Engineering Discipline}

Article contributors may conduct educational studies in several engineering disciplines. In this study, articles that did not focus on specific engineering disciplines were not considered for further analysis.

\section{Research Topic}

According to Sulaiman and AlMuftah (2010)'s classification principle, women studies can be examined from a pipeline perspective, which includes three elements: (a) recruitment (inflow), (b) in-school learning experience (retention), and (c) career development (outflow). These three concepts consist of analysis variables for the research topic.

\section{RESULTS \& DISCUSSION}

\section{Quantity of Research}

Table 2 reports a summary of the quantity of research for women studies. 
Table 2: Summary of Quantity of Research

\begin{tabular}{|l|c|c|c|}
\hline Jear & IJEE & EJEE & JEE \\
\hline 2000 & 2 & 0 & 3 \\
\hline 2001 & 0 & 0 & 2 \\
\hline 2002 & 10 & 0 & 2 \\
\hline 2003 & 1 & 1 & 2 \\
\hline 2004 & 0 & 0 & 0 \\
\hline 2005 & 1 & 3 & 1 \\
\hline 2006 & 1 & 4 & 0 \\
\hline 2007 & 1 & 0 & 2 \\
\hline 2008 & 0 & 3 & 1 \\
\hline 2009 & 0 & 7 & 4 \\
\hline Total & 16 & 18 & 17 \\
\hline
\end{tabular}

From the information listed in Table 2, the total number of women studies published in each journal during a ten-year period is almost equal (IJEE: 16; EJEE: 18; JEE: 17). Women studies in three journals were not published annually. If journals administrators create a special issue on women studies, the number of research papers may be growing (e.g. 2002 in IJEE or 2009 in EJEE).

\section{Author's Geographical Affiliation}

Table 3 shows a summary of the first author's geographical affiliation for women studies published in three engineering education journals. The results indicate that North America is a major area of affiliation for the first author in JEE. Culture diversity exists in IJEE and EJEE since the first authors' affiliations come from several geographical areas. In each journal, few researchers from Middle East and Africa engage in women studies. However, regardless of journal type, no scholars from South America and Asia-Pacific submit their scholarly works to three academic journals.

Table 3: Summary of Author's Geographical Affiliation

\begin{tabular}{|l|c|c|c|}
\hline Area & IJEE & EJEE & JEE \\
\hline North America & 4 & 2 & 15 \\
\hline South America & 0 & 0 & 0 \\
\hline Europe & 7 & 8 & 1 \\
\hline Middle East & 1 & 2 & 0 \\
\hline Asia-Pacific & 0 & 0 & 0 \\
\hline South Asia & 3 & 6 & 0 \\
\hline Africa & 1 & 0 & 1 \\
\hline Total & 16 & 18 & \\
\hline
\end{tabular}

\section{Research Method}

A summary of research method appears in Table 4. The results show that quantitative-based and qualitative-based articles share similar weights. Theoretical inquiry and mixed-methods are not popular research methods in women studies.

Table 4: Summary of Research Method

\begin{tabular}{|l|c|c|c|}
\hline \multicolumn{1}{|c|}{ Journal } & IJEE & \multirow{2}{*}{ EJEE } & JEE \\
\hline Quantitative-based & 6 & 7 & 9 \\
\hline Qualitative-based & 9 & 4 & 5 \\
\hline Theoretical inquiry & 1 & 4 & 1 \\
\hline Mixed-methods & 0 & 3 & 2 \\
\hline Total & 16 & 18 & 17 \\
\hline
\end{tabular}




\section{Research Subject}

The information of research subject is listed in Table 5. The results indicate that most of researchers tend to compare the gender difference by surveying male and female engineering college students at the same time. Female engineers and female college engineering students are also target populations. Female engineering faculty and K-12 female students are not focuses for engineering educators.

Table 5: Summary of Research Subject

\begin{tabular}{|l|c|c|c|}
\hline \multicolumn{1}{|c|}{ Journal } & IJEE & EJEE & JEE \\
\hline Category & 2 & 4 & 1 \\
\hline Female engineering faculty & 0 & 0 & 1 \\
\hline Female Engineer & 7 & 3 & 3 \\
\hline Female college (or graduate) engineering student & 5 & 0 & 4 \\
\hline Male \& female college engineering student & 2 & 10 & 8 \\
\hline K-12 female student & 0 & 1 & 0 \\
\hline Total & 16 & 17 \\
\hline
\end{tabular}

\section{Engineering Discipline}

Table 6 presents a summary of engineering discipline analyzed in women studies. It is found that most scholars often recruit students from several engineering disciplines and would not focus on specific engineering disciplines. Currently, computer engineering is the most discussed engineering discipline.

Table 6: Summary of Engineering Discipline

\begin{tabular}{|c|c|}
\hline $\begin{array}{ll}\text { Journal } & \text { Category } \\
\end{array}$ & Engineering Discipline \\
\hline IJEE & Computer engineering (2) \\
\hline EJEE & $\begin{array}{l}\text { Computer engineering (1) } \\
\text { Construction engineering (1) } \\
\text { Electronic engineering (1) }\end{array}$ \\
\hline JEE & None \\
\hline
\end{tabular}

\section{Research Topic}

Table 7 summarizes the information regarding the research topic in women studies. The results indicate that analyzing female engineering students' learning experiences is a mainstream research trend. Recruitment and career development for female college engineering students are less discussed research topics.

Table 7: Summary of Research Topic

\begin{tabular}{|c|c|c|c|}
\hline Category $\quad$ Journal & IJEE & EJEE & JEE \\
\hline Recruitment & 1 & 2 & 2 \\
\hline Learning experiences & 8 & 11 & 12 \\
\hline Career development & 6 & 3 & 2 \\
\hline *Other issues & 1 & 2 & 1 \\
\hline Total & 16 & 18 & 17 \\
\hline
\end{tabular}

* Topics cannot be categorized.

\section{CONCLUSION}

Through a decade-review process, six analytical approaches, which include quantity of research, author's geographical affiliation, research method, research subject, engineering discipline and research topic, produces the following major findings:

1. Unless the editorial teams for engineering journals create a special issue for women research, the number of annual publication for women studies is limited. 
2. More efforts are needed for promoting women studies in South America and Asia-Pacific.

3. Although mixed-methods methodology is the less used research design in women studies, it can provide powerful evidence by validating quantitative and qualitative data.

4. Current engineering educators did not put female engineering faculty and K-12 female students as research priority groups.

5. Researchers tend to focus on general engineering and seldom specify certain engineering disciplines.

6. The current trend of research topic centers on female college engineering students' learning experiences.

The findings yielded in this study serve as research guidelines for scholars who try to explore women issues in engineering education. It is expected that future studies may fill the research gaps identified in the findings.

\section{AUTHOR INFORMATION}

Pao-Nan Chou, Department of Education, National University of Tainan. E-mail: pnchou@ mail.nutn.edu.tw

\section{REFERENCES}

1. Beddoes, K. \&Borrego, M. (2011). Feminist theory in three engineering education journals: 1995-2008. Journal of Engineering Education, 100(2), 281-303.

2. Chou, P. -N., \& Chang, C. -C. (2010). Research characteristics and patterns in engineering education: content analysis, 2000-2009. World Transactions on Engineering and Technology Education, 8(4), 462-470.

3. Dobson, I. R. (2012). It's a man's world: the academic staff gender disparity in engineering in 21 st Century Australia. Global Journal of Engineering Education, 14(3), 213-218.

4. JEE (2006). The research agenda for the new discipline of engineering education. Journal of Engineering Education, 95(4), 259-261.

5. Jesiek, B. K. et al. (2011). Mapping global trends in engineering education research, 2005-2008. International Journal of Engineering Education, 27(1), 77-90.

6. Neuendorf, K.A. (2002). The content analysis guidebook. Thousand Oaks, CA: Sage.

7. Sulaiman, N. F. \& AlMuftah, H. (2010). A Qatari perspective on women in the engineering pipeline: an exploratory study. European Journal of Engineering Education, 35(5), 507-517. 